\title{
The Place of the Library in the Evaluation of Graduate Work
}

\begin{abstract}
Traditional, time-honored methods of evaluating the adequacy of academic libraries for graduate work are no longer adequate in themselves. Rising numbers of students, changing degree programs, and advancing costs are rendering traditional evaluation methods less and less adequate. Greater attention should be devoted to the assessment of research collections in the region, to pondering new kinds of library plant needs, to rethinking the use of library personnel, to seeking new systems for funding library operations, and to articulating librarians more completely into the university community.
\end{abstract}

1 MPLiCIT IN THE TITLE of this paper is the conjecture that the presently organized system for judging the adequacy of a library for graduate purposes is not good enough. With such an implication in view, this paper will touch upon various aspects of the library and its work, briefly noting present methods of evaluation and suggesting major movements which might be considered to supplement them. Let us begin with the library's collections, since through long tradition we may be convinced that the library is its book collection. The Council of Graduate Schools' leaflet on The Doctor of Philosophy Degree says, "The library should, of course, contain extensive materials in the given field, both of a gen-

Dr. Orne is University Librarian in the University of North Carolina. This paper was read before a Conference on the Evaluation of Graduate Education, sponsored by the Commission on Colleges of the Southern Association of Colleges and Schools, June 24-25, 1968, in Atlanta, Georgia. eral and specialized nature. Library materials available on loan or at other institutions are helpful but not sufficient." Its leaflet on The Master's Degree says, "The library should, of course, contain far more extensive materials than are usually present in an undergraduate library." These fairly general statements are extended a little in the final citation, the CGS leaflet on new PhD programs. It cites one of very few numerical measures, the allusion to a basic one hundred thousand volumes for a solid undergraduate college library, plus more general statements referring to the number of areas in which the degree is to be given. No one can argue with the correctness of these statements. One can, however, contest their adequacy. The latter leaflet also recognizes access to other resources, when it says, "It is important to make provisions for procuring research materials from sources outside the university and when necessary to allow for travel expenses to other libraries with specialized holdings not locally available."

In a recent article, Dr. Robert $B$. 
Downs wrote, "It seems doubtful that high-level doctoral work in a variety of fields can be carried on with less than half a million volumes and with annual book expenditures under $\$ 200,000$."1 In this year's guide for grant proposals issued by the Office of Education appears the following statement as one measure: "An institution offering $\mathrm{PhD}$ programs should have five hundred thousand volumes for its first degree program and fifty thousand additional volumes for each additional $\mathrm{PhD}$ program." While these statements have not yet become criteria for evaluation, they will be used, rightly or wrongly, wherever they may be expedient to various purposes. It is just such statements that lead to specious devices for measuring the mirages which sometimes are conjured up to cloud an issue.

We are now faced with a rapidly evolving change in the whole concept of graduate education and with other influences that must affect its evaluation. The first of these is numbers; this affects all of our topics. The second is changing degree programs, changing as to content and time scale; and the last is cost. Each of these has a profound effect upon the library and suggests attention to other considerations for measuring collections.

Most large institutions with extensive graduate programs are now finding ways to provide basic collections for undergraduate use and others, far more extensive, for their graduate programs. This is reflected in published lists of basic undergraduate titles, and usually in separate locations for the several levels of bibliographical support. It is often represented in numerous subject libraries found outside of the main library, or on separate floors of new multi-story libraries.

Certainly the number of programs

1 "Doctoral Programs and Library Resources," CRL, XXVII (March 1966), 129. must be carefully scrutinized. It is easier to measure a young institution now offering its first or early graduate programs than an older one which may be deficient for half of those offered.

Costs are now so high that the measure of library adequacy must be somehow broadened to encourage considerable and responsible sharing of resources. The cost of materials and their incorporation into libraries, considering the vast numbers of new institutions, has reached such a level as to give us pause. It is now not only impractical but downright foolhardy for any institution to presume it can depend entirely upon its own resources, even for a few fields of graduate work.

Every current movement points to closer coordination or cooperation, and funding sources everywhere are feeling new pressures to promote such efforts. On the federal level many grant opportunities are tied to joint-use proposals. On the state level there are steadily increasing numbers of consolidated systems, some of which are already found in Southern states. In large cities, such as New York, one finds extensive consolidation. Consortia of various types have been with us for many years. All of these are heavily influenced by costs, and this compels our attention to their use in new measures.

Libraries and librarians today are vitally concerned with consolidating resources; they are keenly aware of the imperatives of costs and numbers, often much more so than their academic principles. The librarian can and will measure his available resources, and with the systems concepts now springing up, can often advise positively of reasonable availability when resources needed are not right at hand. There are numerous library networks now being formed to provide types and levels of access never before possible and never before so desperately needed to enable the support of burgeoning graduate programs. 
The critical point to be made with respect to collections is that while our previous measures were and remain sound, a much more liberal view will have to be taken of resources not on site. One may also have to count as one resource the readiness and capacity of the librarian to assess and utilize well a broader spectrum of resources than those in his own charge.

Any consideration of the physical facilities used by libraries leads to similar thoughts. Present measures provide again fairly general statements, plus one specific. The library standard calls for "Proper seating accommodations ... for at least one-fourth of the largest number of students on the campus at any one period of the day. In areas of graduate study and research, carrels which may be individually assigned should be provided. Conference rooms and seminars are highly desirable. . . ."2 Standard 10 makes no specific mention of library space.

The problems of numbers have forced solutions which might otherwise never have been found in libraries. A Bunyanesque step was taken with the advent of the separate undergraduate library. The enormous expansion of undergraduate student numbers has made omnipurpose libraries unsuited for the serious, intensive study of the researcher, and unconscious pressures have combined to force the separation. Another major change is seen in the increasing spread of individual carrel provision, even in the open reading areas of undergraduate or general libraries. The noise and traffic accompanying large numbers has led even the less-serious undergraduate to concern for his time in the library. And finally, because a faculty office is no longer a haven, increasing numbers of faculty studies are found in new library structures.

${ }^{2}$ Southern Association of Colleges and Schools, Standards of the College Delegate Assembly (Atlanta: SACS, 1966), p. 18.
Increasing numbers of graduate programs are compelling a restudy of views concerning central versus separate facilities. Today new graduate and research programs often require specialized resources, either separate or jointly used, beyond any regular uses of the parent institution. Physical decentralization is often forced upon us, and we find that it is not at all bad, so long as bibliographical control is still possible. This is little different from accepting the sharing of resources in a number of neighboring institutions, a practice long used to avoid pointless duplication.

We have also learned more about compelling relationships between subject fields, and we can be wiser in planned decentralization. There are now more bio-medical libraries, science libraries, and other viable combinations, wherever the volume of graduate work warrants such structures. Once more numbers and costs have taught good lessons.

Circumstances require a new look in yet one other area. Present standards put a premium on direct access to the book collections, and for decades this has been considered one of the essential perquisites of the graduate students and faculty. Yet many are now impressed by the relative unimportance of browsing, long touted as the best avenue to discovery. The volume of published material in almost any given field is so great that browsing is well-nigh impossible and usually unproductive. Libraries in many institutions most dedicated and productive of research in other countries have never allowed free access to central collections and indeed have never been concerned with subject classification to any great degree. Accession number shelving by two or three sizes seems not to have inhibited productive use of these libraries.

More critical for the future will be special kinds of space and some new space relationships. Libraries are moving 
steadily towards computer use, towards new functions as communications and distributing centers. Thus measurement of libraries will have to include, in addition to all standard physical necessities, facilities for promoting swift and comprehensive access to a larger world of regional or national resources. Specifically, library structures will need suitable spaces for computer centers, extensive photocopying facilities, and communications centers, each with its particular staff.

There are some changes needed in measuring library staffing, due more to new methods than to either numbers of students or costs. The current standard speaks briefly and in fairly general terms to the numbers of staff members and expenditures for staff. Librarians themselves have attempted the establishment of statistical measures as well as classification and pay plans. The academic status of librarians continues to be a contentious topic. One unquestioned criterion is the acceptance of a degree from an ALA-accredited library school as making a professional librarian. Obviously, accrediting agencies have a high regard for their peers. None of this is said to suggest elimination of these useful measures, but to restate those in use. There are, however, some additional criteria which might be considered as supplements or substitutions.

Libraries of great research institutions today have discovered and accepted the need for new types of staff, formerly unknown or disguised under the inappropriate title of librarian. Specially trained personnel to man the computer center, the photocopying center, and the communications center are often highly trained professionals, but they are not necessarily librarians. In fact, to insist on the title may make the manning of such positions impossible.

Another rapidly expanding staff area is that of the subject bibliographers. Such staff members now increasingly serve the collection-building needs of a library, as the faculty retreats more and more from bibliographical chores.

Finally, it is now generally recognized that the new librarianship is sharpening its use of manpower by separating professional from clerical skills to attain a more rational proportion of the numbers of each type needed to serve these new and different functions as well as the older ones.

Future measures of library staffing should include not only numbers or costs, but more specifically the types of professionals available and their special qualifications for new methods of service. Graduate programs must be supported in the library not only by major bibliographical resources but by trained personnel for assuring intensive access to them. The potential usefulness of such a professional staff can be seriously prejudiced, if not completely vitiated, by inadequate clerical support to free the professional for entirely professional service. $^{3}$ The library administration must be capable of using these varied talents well to constitute a harmonious and effective service agency. The basic difference between evaluation of the usefulness of the library for graduate education and for the undergraduate program might be described in a few words as the difference between serving materials and serving people. Better evaluation of the library as an apt agency for serving graduate programs might be achieved by examining closely how well its staff is organized to serve the users, rather than to serve materials.

It is in the area of evaluating financial support that present measures of the library are woefully deficient. Dependence now rests, in large measure, upon statistical devices of questionable reliability. Furthermore, the subliminal influences of such measures sometimes re-

${ }^{3}$ This is much more critical for graduate programs than at lower levels. 
sult in changes so crudely effective as to inhibit truly responsible improvement.

Evaluators now begin by comparing like institutions, using size of library, overall expenditures, expenditures for library materials, expenditures per student, and other such distinctive periodic statistics. They have also one rule of thumb, which is based upon a percentage of the total educational expenditure of the parent institution. The only virtue these figures possess is that it is usually possible to obtain a chronological series and fairly comparable statistics from a number of sources. The reliability or integrity of any of these magical numbers is not nearly so virtuous.

It is well-nigh impossible to get uniform, comparable, or unbiased statistical reporting from any group of institutions, despite (or perhaps because of) the earnest intentions of those concerned. The character and measures of one institution seldom conform to those of another. The size of a library may be grossly inflated by the inclusion of varying types of materials or simply by a method of counting. The per-student cost ratio may be totally lacking in significance in varying types of institutions. How can a per-student cost at Michigan State, with 40,000 students, be compared to that of Duke University, with fewer than 6,000 students? Their libraries are nevertheless approximately the same size! Obviously, a different kind of collection is needed to serve 40,000 than a student body of 6,000 would require.

Comment should also be made on the educational budget percentage figure frequently cited as a measure, usually stated as 5 per cent. In recent years, ever fewer large libraries have reached or maintain this level, and if it is claimed, the calculations may be deviously combined to prove it. The simple fact is that there are too many variables to make this a reliable measure. Newer institutions must spend a very large percentage of their budget to build up a library quickly. Older institutions have their historic accumulation already in place and benefit considerably from gifts. A dozen other variables could be cited to demonstrate further the hopelessness of a percentage measure, but conclusive evidence can be found in the chronological record of a single institution over a long period of time. In many such instances, a highly regarded library improves on a gradually decreasing percentage of a growing institution's educational budget.

Future measures of financial support especially significant for graduate programs will need to consider far more variables than ever before, and any statistical measure will have to rely more heavily on current circumstance than upon historical precedent. Among these current variables are the widely differing levels of demand for library resources, as between laboratory sciences and the humanities. Also important are significant differences in unit cost, for art books and literary monographs, or between music scores and economic treatises. Many similar divergences could be cited. Another complex variable is the level of production in various subject areas. Literary and historical book production outnumbers the publication of math or physics titles by a factor of hundreds.

On a totally different track, the constantly changing aspect of academic involvement in grants and contract research often creates an aggravating imbalance in the research library. The library is often neither consulted nor included in the financial benefits accompanying such ventures. When through strange circumstance it is included, this may result in short-lived and embarrassingly inequitable surfeit in one area while other critical needs continue on short rations. These difficulties are perhaps enough to illustrate the complexity 
of the problem. Though not pretending to any universal solution, a few points might be suggested which future standard measures will have to consider. They do not simplify the problem.

The new technology, now only beginning to be applied by research libraries, will soon substitute certain machine operations for either the codex book, staff, or both. Yet these costs will be bona fide library expenditures and must be recorded as such. In a simple form the expense may be only the cost of a tenpage give-away Xerox copy of a needed article. A more expensive example might be a telefacsimile printout purchased from the American Chemical Society in Columbus, Ohio, of a small number of abstracts selected by its computer center from thousands of entries on a specific topic. Other library costs may be assigned to mechanical tools supplementing the on-site repertory of library resources. Rentals or purchase of new machines, communication lines, and the cost of staff to service them will be taking an ever larger part of library budgets. How can this fail to affect expenditures for books and journals? In many fields the rapid expansion of indexing and analytical services has out-paced and out-priced the traditional acquisitions pattern.

Other influences affecting staff will enter into the new complex. Professional associations and labor unions are making their strength known in ways that cannot be disregarded. The incredible manpower shortage, which has recently forced an improvement in the use of professional time, will also affect any review. The use of a wider range of types of professionals will make the library staff a more complex instrument to assess, but evaluation must be made of the entire resource, of which the staff is critical in serving graduate education. The professional will be increasingly professional, more expensive, and more demanding of privilege and recognition.
All of these facts will affect costs.

Another aspect of the research library that will require increasing attention is its public relations. Until recently general opinion has too often held that a great library, like a small child, should be seen but not heard. Its primary contact with the senior faculty was through a library committee, now a rapidly diminishing influence if not an anachronism.

The library has always maintained good working relationships with its peer institutions, mainly through the loosely organized interlibrary loan convention. It has also served its less-blessed neighboring institutions, though often with illgrace and occasionally with crusty denial.

The library's present relationship to its parent administration was aptly expressed in a recent journal article title, "The Bottomless Pit, or the Library as Seen by an Administrator." ${ }^{\prime}$ This may be taken as a token of deteriorating relationships between the harried administrator on one side and the beleaguered librarian on the other. If such a condition persists, it could be highly prejudicial to effective development of the library for graduate study.

Future evaluation of a library for graduate-level service might well give more attention to some activities, seemingly unrelated to research, but in fact the sine qua non of the successful research library. The first of these is the place of the library and its staff in the academic community. This place can be established only by frequent direct contact or interaction between librarians and faculty. There must be good twoway communication or poor service will follow. Librarians must participate actively in academic chores, serving on faculty committees and sharing the burdens of academic protocol. The faculty must plan with the library to assure

\footnotetext{
"Robert F. Munn, "The Bottomless Pit, . ." CRL, XXIX (January 1968), 51-54.
} 
availability of needed resources at the time and place needed. This has been said before, of course, and all agree on the need for such action. What is now added is an urgency, a considerable increase in demand for the fact, not the word. It is no longer possible for either the faculty or the librarians to wend their separate ways. Current pressures for information, better analysis of materials, swifter access, and far greater provision of materials compel a sharing of endeavor beyond anything previously known in the world of learning.

A large part of the success of the research library today can be measured by its place in its own professional community, that is, the community of American research libraries and similar regional associations. Most planning for joint use of major resources, for programs designed to extend or broaden services, and for staff development has been initiated by such groups. Those few quantitative or evaluative devices now in existence were started and are maintained by them. Granting the difficulties and imperfections of such measures, they represent some of the few comparative measures we have over a statistically reliable period of time.

These same professional organizations include the leadership of planning groups devising local, regional, and national systems. The fundamental basis of the need for such systems is the service of graduate study and research. These mutual aid systems, now called "networks," are an essential part of any major library concerned with graduate programs of study or research. These relationships will acquire increased importance as graduate study is extended on any campus and as graduate programs grow across the country.

In summary, the evaluation of a library for its capacity to serve graduate study requires more specific study of the collections beyond the basic under- graduate collection. It must give particular attention to related materials within a broad service area and determine the extent to which they may be utilized.

Library buildings and tenant space require new views of separation or decentralization, depending largely upon numbers. Individual seating now has far greater importance and must be noted. Even the idea of open access is now once more in question. Special spaces within libraries for new tools or methods will count heavily toward effective service to graduate students.

The library staff must be examined closely to determine how they serve, and how professional librarians are used. Other professionals (non-librarian) will be counted in increasing numbers. The ratio of professional to sub-professional and clerical staff is often revealing.

The financing of libraries grows constantly more difficult to evaluate. Expenditures must now be more specifically related to the levels of work and subject fields involved. Increased importance may be assigned to shared use and shared costs. New costs accompanying new devices, methods, and their specialized staffs will skew present total cost measures.

Finally, the place of the library, and its staff, in the world in which they live and work, will need far more than the usual platitudes of full acceptance. Only genuine sharing of academic planning and full participation in developmental groups can serve to assure competent preparation for graduate programs. It is incumbent upon the evaluator to verify the true extent of these essential relationships.

It is clear that the task grows ever more complex; this is the mode of our time. There are those who believe that if something is harder, it must be better. If this be true, we are getting better all the time. 